\title{
Food insecurity is associated with food consumption patterns and anthropometric measures but not serum micronutrient levels in adults in rural Tanzania
}

\author{
Germana H Leyna ${ }^{1,2, *}$, Elia J Mmbaga ${ }^{1}$, Kagoma S Mnyika ${ }^{1}$, Akhtar Hussain ${ }^{3}$ and \\ Knut-Inge Klepp ${ }^{2}$ \\ 'Department of Epidemiology and Biostatistics, Muhimbili University of Health Sciences, Dar es Salaam, \\ Tanzania: ${ }^{2}$ Department of Nutrition, Faculty of Medicine, University of Oslo, PB 1046-Blindern, N-0316, Oslo, \\ Norway: ${ }^{3}$ Department of General Practice and Community Medicine, University of Oslo, Oslo, Norway
}

Submitted 19 November 2008: Accepted 20 January 2009: First published online 3 March 2010

\begin{abstract}
Objective: The purpose of the present paper is to assess the relationship between food insecurity and food consumption patterns, anthropometric measures and serum micronutrient levels in rural Kilimanjaro, Tanzania.

Design: A population-based cross-sectional study was carried out between March and May of 2005.

Setting: Rural Kilimanjaro, Tanzania.

Subjects: Analysis was restricted to 1014 adults aged 15-44 years with children and complete data.

Results: A large majority of the participants (91\%) reported some kind of food insecurity. Food insecurity was significantly associated with age, marital status and occupation. Participants reporting food insecurity were significantly less likely to frequently consume animal products, fruits and vegetables compared with participants categorized as food secure. Women categorized as experiencing individual food insecurity had a larger waist circumference than food-secure women $(P=0.026)$ while the mean BMI of women appeared to decline if they had a child who was food insecure $(P=0 \cdot 038)$. There were no observed differences in serum micronutrient levels by food insecurity status.

Conclusions: Food insecurity is highly prevalent and associated with food consumption patterns, waist circumference and BMI of women in rural Tanzania. Further studies should apply self-report measures in assessing food insecurity to larger and more diversified populations.
\end{abstract}

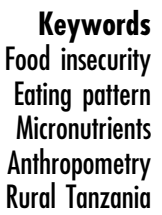

Keywords Food insecurity Eating pattern Anthropometry Rural Tanzania
Food insecurity is a public health concern in both developed and developing countries, affecting the urban and rural poor. Food security is defined by the World Food Summit as a state where 'all people, at all times, have physical and economic access to sufficient, safe and nutritious food to meet their dietary needs and food preferences for an active and healthy life ${ }^{,(1)}$. Globally it is estimated that about 854 million people are food insecure, with 820 million of these living in developing countries $^{(2)}$

Poor dietary intake is described as an integral characteristic of food insecurity that may result in poor nutritional state and quality of life ${ }^{(3)}$. Recent methodological advances in the measurement of food insecurity have allowed exploration of the influence of food insecurity on dietary consumption of adults in both developed $^{(4-7)}$ and developing countries ${ }^{(8-10)}$. These studies have revealed that food insecurity is associated with lower intakes of meat and dairy products, fruits and vegetables, as well as lower consumption of nutrients that may result in poor nutritional status and health ${ }^{(4,5,7,8,10)}$. These findings have forged a path for dietary data to be used in validation of questionnaire-based food insecurity measures in developing countries ${ }^{(11,12)}$.

Dietary patterns from most developing countries and in particular African countries are described as monotonous, comprising foods low in energy, few animal products and fruits and vegetables ${ }^{(8,13-16)}$. These patterns are increasingly being named responsible for the high rates of malnutrition and micronutrient deficiencies observed in these countries, although other non-food related factors may also partly explain the magnitude observed ${ }^{(17)}$. In light of the predicted increase in the magnitude of food insecurity in East Africa $^{(2)}$ and the latest crises in food 
prices, there is a need for simple instruments that can assess dietary patterns accurately, timely and cost-effectively. The use of questionnaire-based food insecurity instruments may fill in this crucial gap.

Using a recently adapted and validated Radimer/Cornell food insecurity measure for use in rural Tanzania ${ }^{(18)}$, we hypothesized that food insecurity (assessed by a questionnaire-based instrument) may predict decreased dietary intake and result in a continuum of negative outcomes, namely micronutrient deficiencies and poor nutritional status.

\section{Methods}

\section{Study area and subjects}

The study was conducted in Oria village, Moshi Rural district. The village is located at the foot of Mount Kilimanjaro, a few kilometres from the Tanzania-Kenya border and about $30 \mathrm{~km}$ south of the regional administrative capital, Moshi. The population mainly consists of peasants who grow maize, paddy and vegetables; petty businessmen selling agricultural products and fish; and a few employed individuals. The village has a weekly market selling a variety of commodities from fruits and vegetables to clothes and shoes. It is used by local and neighbouring villagers and by business people from Moshi town. A detailed description of the study area is given elsewhere ${ }^{(19)}$.

\section{Study design and survey procedure}

A cross-sectional study was carried out in Oria village between March and May of 2005. Before onset of the study, house-to-house registration of all eligible participants (aged 15-44 years with a permanent address in the village) was performed by trained research assistants with support from village and hamlet leaders. A total of 2093 individuals were listed and invited to participate. Consenting individuals were interviewed by the research team in or near their homes. The ethical committees of the Tanzania Ministry of Health and the Norwegian Committee for Medical Research reviewed and approved the study protocol.

\section{Questionnaire data}

All participants responded to questions on demographic characteristics, food insecurity items and a short FFQ. Food insecurity was assessed using an adapted version of the Radimer/Cornell food insecurity scale whose validity and reliability have been established in this setting ${ }^{(18)}$. We defined a participant as 'food secure' if they responded 'never' to all of the Radimer/Cornell items; as 'individual food insecure' if they responded 'sometimes' or 'always' to items on anxiety to food depletion, monotony in diet or decreased individual food intake; and 'child food insecure' if they responded 'sometimes' or 'always' to any of the child items.

\section{Dietary assessment}

Dietary intake was assessed by using a thirty-eight-item FFQ. Participants were asked on average how often in the past month they had consumed each food item (e.g. meat/eggs/oranges/amaranth leaves, etc.). There were five response categories: 'every day', 'several times a week', 'once a week', 'once or twice a month' and 'less than once a month/rarely/never'. The FFQ was pre-tested with a convenience sample of 150 and has been previously used in this study area ${ }^{(20)}$. To ease analysis, the food items were condensed into eight simpler food group categories. A summary measure of frequent consumers was determined as eaten 'several times weekly' for fruits and vegetables and 'at least weekly' for animal products. This categorization has been used by other studies ${ }^{(8)}$.

\section{Antbropometric measures}

Height was measured to the nearest $0 \cdot 1 \mathrm{~cm}$ using locally made portable devices equipped with height gauges and weight was measured using calibrated portable electronic scales to the nearest $0 \cdot 1 \mathrm{~kg}$ with participants wearing light clothing and no shoes. Waist and hip circumference was measured by trained research assistants (waist measured at the level of the umbilicus and hip measured horizontally at the level of the greatest lateral extension of the hips) with participants standing, using non-stretchable tape measures; and used to construct waist:hip ratio (WHR) $(\mathrm{cm} / \mathrm{cm})$. Measurements were conducted in duplicate and an average value was used for the analysis. BMI was calculated as $\mathrm{kg} / \mathrm{m}^{2}$ and classified as proposed by $\mathrm{WHO}^{(21)}$. Participants were classified as underweight (BMI $<18.5 \mathrm{~kg} / \mathrm{m}^{2}$ ), normal weight $\left(\mathrm{BMI}=18 \cdot 5-24 \cdot 9 \mathrm{~kg} / \mathrm{m}^{2}\right)$, overweight $(\mathrm{BMI}=25 \cdot 0-29 \cdot 9 \mathrm{~kg} /$ $\mathrm{m}^{2}$ ) or obese $\left(\mathrm{BMI} \geq 30 \cdot 0 \mathrm{~kg} / \mathrm{m}^{2}\right)$. Central obesity was defined as a WHR of $\geq 0 \cdot 85$ for women and $\geq 0 \cdot 95$ for men.

\section{Serum micronutrients}

Blood was drawn from the antecubital vein of each participant into a $5 \mathrm{ml}$ Vacutainer tube wrapped with black tape. The blood samples were stored in insulated cool boxes for transportation to the Kilimanjaro Christian Medical Hospital laboratory. The blood samples were centrifuged at $2000 \mathrm{rpm}$ for $15 \mathrm{~min}$ at room temperature within $8-10 \mathrm{~h}$ of collection. The sera were then separated into Nunc tubes also wrapped with black tape and labelled with sample number. The plasma samples were subsequently stored in a freezer at $-20^{\circ} \mathrm{C}$ and flown to Norway for analysis by VITAS AS laboratories. Serum retinol concentration was determined by HPLC and serum ferritin was measured by ELISA. Iron stores were characterized on the basis of serum ferritin concentration as depleted when $<15 \mu \mathrm{g} / 1$ and vitamin A status was characterized as deficient if serum retinol concentration was $<0 \cdot 70 \mu \mathrm{mol} / 1$.

\section{Statistical analysis}

Data were analysed using the SPSS for Windows statistical software package version $14 \cdot 0$ (SPSS Inc., Chicago, IL, 
USA). Descriptive statistics were used to depict overall distribution of the variables. ANOVA was used to describe means and standard deviations for continuous variables according to food insecurity status. Prevalences of categorical variables were evaluated with contingency tables, expressed as percentages, and accompanied by the $\chi^{2}$ test for differences in proportion. We examined the outcome food insecurity status in relation to demographic characteristics using three categories (food secure, food insecure at individual level and food insecure at child level). In logistic regression models two dummy variables were created from food insecurity status, food insecure at individual level and food insecure at child level; the category food secure was used as the reference. We evaluated the association between food insecurity status and food consumption patterns using a summary measure where one term for frequent consumption was used. We employed analysis of covariance to examine whether anthropometric measures differed by food insecurity status controlling for potential confounders. Since sex contributes to the variation observed in both food insecurity status and anthropometric measures, we examined for possible differences among men and women separately. Finally, we examined the association between food insecurity status and serum micronutrient levels. In our multivariable logistic models we considered age, sex, marital status, education and occupation as potential confounders. Our results are given as odds ratios and their 95\% confidence intervals. Significance was set at $P<0 \cdot 05$.

\section{Results}

A total of $1528(73 \%)$ adults aged between 15 and 44 years participated in the survey. Of these, 452 (30\%) did not have children and sixty-two (4\%) had missing data for either one or more of the food insecurity items or demographic variables. In the analysis presented herein, 1014 adults were included with anthropometric measurements available for 1006 (99\%) subjects. There was no difference in the distribution of demographic characteristics and food insecurity status between participants with and without anthropometric measurements.

\section{Food insecurity and demographic characteristics}

Food insecurity was prevalent with $91 \%$ of the subjects reporting some kind of food insecurity (food secure, 9\%; individual food insecure, $37 \%$; child food insecure, $54 \%$ ). Table 1 shows the prevalence and odds ratio of food insecurity status according to demographic characteristics. Food insecurity was associated with age, marital status and occupation. The adjusted odds ratio (AOR) for food insecurity at the individual level, compared with food secure, for age groups $21-30$ years, $31-40$ years and $\geq 41$ years respectively, was $1.23(95 \% \mathrm{CI} 0 \cdot 67,2 \cdot 24), 2 \cdot 57$ (95\% CI $1 \cdot 39,4 \cdot 75)$ and $6 \cdot 10(95 \% \mathrm{CI} 3 \cdot 07,12 \cdot 11)$. Married participants were less likely to report individual food insecurity compared with single participants (AOR $=0 \cdot 36 ; 95 \% \mathrm{CI}$ $0 \cdot 21,0 \cdot 59)$. Further analysis revealed that this association was limited to males $(\mathrm{AOR}=0 \cdot 07 ; 95 \%$ CI $0 \cdot 01,0 \cdot 26)$.

Table 1 Prevalence and odds ratio of food insecurity status according to sociodemographic characteristics among adults aged 15-44 years with children in rural Kilimanjaro, Tanzania, 2005

\begin{tabular}{|c|c|c|c|c|c|c|c|c|}
\hline \multirow[b]{2}{*}{ Variable } & \multirow[b]{2}{*}{$n$} & \multirow{2}{*}{$\frac{\text { Food secure }}{\%}$} & \multicolumn{3}{|c|}{ Individual-level food insecurity } & \multicolumn{3}{|c|}{ Child-level food insecurity } \\
\hline & & & $\%$ & AORt & $95 \% \mathrm{Cl}$ & $\%$ & AORt & $95 \% \mathrm{Cl}$ \\
\hline \multicolumn{9}{|l|}{ Age group } \\
\hline$<21$ years & 73 & $16 \cdot 4$ & $26 \cdot 0$ & $1 \cdot 00$ & ref & $57 \cdot 5$ & $1 \cdot 00$ & ref \\
\hline $21-30$ years & 423 & $12 \cdot 5$ & $26 \cdot 5$ & $1 \cdot 23$ & $0 \cdot 67,2 \cdot 24$ & $61 \cdot 0$ & $1 \cdot 04$ & $0.61,1 \cdot 75$ \\
\hline $31-40$ years & 388 & $5 \cdot 4$ & $41 \cdot 2$ & $2 \cdot 57^{\star \star \star}$ & $1 \cdot 39,4 \cdot 75$ & $53 \cdot 4$ & $0 \cdot 70$ & $0 \cdot 41,1 \cdot 21$ \\
\hline$\geq 41$ years & 130 & $4 \cdot 6$ & $62 \cdot 3$ & $6 \cdot 10^{\star \star \star}$ & $3 \cdot 07,12 \cdot 11$ & $33 \cdot 1$ & $0 \cdot 29^{\star \star \star}$ & $0.15,0.55$ \\
\hline \multicolumn{9}{|l|}{ Sex } \\
\hline Men & 313 & $5 \cdot 8$ & $42 \cdot 3$ & $1 \cdot 00$ & ref & $51 \cdot 8$ & $1 \cdot 00$ & ref \\
\hline Women & 701 & $10 \cdot 6$ & $34 \cdot 1$ & 0.84 & $0.62,1 \cdot 14$ & $55 \cdot 3$ & $1 \cdot 00$ & $0.75,1 \cdot 34$ \\
\hline \multicolumn{9}{|l|}{ Marital status } \\
\hline Single & 79 & $7 \cdot 6$ & $49 \cdot 4$ & $1 \cdot 00$ & ref & $43 \cdot 0$ & $1 \cdot 00$ & ref \\
\hline Married/cohabiting & 801 & $10 \cdot 1$ & $33 \cdot 3$ & $0 \cdot 36^{\star \star \star}$ & $0.21,0.59$ & $56 \cdot 6$ & $2 \cdot 01^{\star \star \star}$ & $1 \cdot 23,3 \cdot 27$ \\
\hline Separated/divorced/widowed & 134 & $3 \cdot 7$ & $49 \cdot 3$ & 0.62 & $0 \cdot 33,1 \cdot 12$ & $47 \cdot 0$ & $1 \cdot 50$ & $0 \cdot 83,2 \cdot 70$ \\
\hline \multicolumn{9}{|l|}{ Education level } \\
\hline No education & 136 & $3 \cdot 7$ & $41 \cdot 2$ & $1 \cdot 42$ & $0 \cdot 75,2 \cdot 64$ & $55 \cdot 1$ & $1 \cdot 20$ & $0 \cdot 66,2 \cdot 14$ \\
\hline Primary & 800 & $9 \cdot 4$ & $36 \cdot 4$ & $1 \cdot 24$ & $0 \cdot 73,2 \cdot 11$ & $54 \cdot 3$ & $1 \cdot 04$ & $0.64,1.69$ \\
\hline Secondary+ & 78 & $15 \cdot 4$ & $32 \cdot 1$ & $1 \cdot 00$ & ref & $52 \cdot 6$ & $1 \cdot 00$ & ref \\
\hline \multicolumn{9}{|l|}{ Occupation } \\
\hline Peasant & 860 & $8 \cdot 7$ & $35 \cdot 9$ & $0.63^{*}$ & $0.42,0.92$ & $55 \cdot 3$ & $1 \cdot 52^{\star}$ & $1 \cdot 05,2 \cdot 18$ \\
\hline Others & 154 & $11 \cdot 0$ & $40 \cdot 9$ & $1 \cdot 00$ & ref & $48 \cdot 1$ & $1 \cdot 00$ & ref \\
\hline \multicolumn{9}{|l|}{ Ethnicity } \\
\hline Chagga & 271 & $8 \cdot 5$ & $34 \cdot 3$ & NS & & $57 \cdot 2$ & NS & \\
\hline Pare & 291 & $13 \cdot 1$ & $36 \cdot 4$ & NS & & $50 \cdot 5$ & NS & \\
\hline Others & 452 & $6 \cdot 9$ & $38 \cdot 3$ & NS & & $54 \cdot 9$ & NS & \\
\hline
\end{tabular}

ref, reference category.

tOdds ratio adjusted for age, sex, marital status, education level and occupation

Statistical significance: ${ }^{\star} P<0.05,{ }^{\star * \star} P<0.001$. 
Finally, peasants were less likely to report food insecurity at the individual level compared with respondents reporting other occupations (AOR $=0.63 ; 95 \%$ CI 0.42, 0.92).

Food insecurity at the child level was associated with age, marital status and occupation. In multivariable logistic regression, adults aged $\geq 41$ years were less likely to report child food insecurity than adults aged $<21$ years $(\mathrm{AOR}=0 \cdot 29 ; 95 \% \mathrm{CI} 0 \cdot 15,0 \cdot 55)$. There was a significant and positive association between food insecurity at child level and marital status $(\mathrm{AOR}=2 \cdot 01 ; 95 \% \mathrm{CI} 1 \cdot 23,3 \cdot 27)$ and being a peasant (AOR $=1 \cdot 52 ; 95 \%$ CI $1 \cdot 05,2 \cdot 18)$.

\section{Food insecurity and food consumption patterns}

The distribution and likelihood of food consumption by food insecurity status is depicted in Table 2 . There was evidence of a strong and significant negative trend in the prevalence of frequent fruits and vegetables, meat, chicken and eggs consumption and food insecurity status. There was no marked difference in fish consumption across the food insecurity groups.

\section{Food insecurity and anthropometric measures}

The mean (SD) anthropometric measurements for the study population were: height $160 \cdot 0(8 \cdot 4) \mathrm{cm}$; weight $56.6(9.7) \mathrm{kg}$; waist circumference $77 \cdot 3(11 \cdot 8) \mathrm{cm}$; hip circumference $91.3(11.7) \mathrm{cm}$; WHR $0.68(0 \cdot 18)$ for men and $0 \cdot 61(0 \cdot 14)$ for women; and BMI $22 \cdot 2(3 \cdot 7) \mathrm{kg} / \mathrm{m}^{2}$. The majority of participants were categorized as having normal weight (69\%) followed by overweight (18\%); the rest were underweight $(8 \%)$ or obese $(5 \%)$. The mean BMI and waist circumference of women varied with food insecurity status. Women categorized as having children experiencing food insecurity had lower mean (SD) BMI values than women who were food secure: $22 \cdot 3$ (3.9) $v$. $23.3(3.9) \mathrm{kg} / \mathrm{m}^{2}(P=0 \cdot 038)$. Also women experiencing food insecurity at the individual level had higher mean (SD) waist circumference than women reporting food security: $80 \cdot 1(10.5) v .78 \cdot 0(9 \cdot 7) \mathrm{cm}(P=0.026)$. Other anthropometric measures did not differ according to food insecurity status (Table 3). Bivariate analysis showed borderline significance of the percentage of women with

Table 2 Distribution and likelihood of food consumption by food insecurity status among adults aged 15-44 years with children in rural Kilimanjaro, Tanzania, 2005

\begin{tabular}{|c|c|c|c|c|c|c|c|c|}
\hline \multirow[b]{2}{*}{ Food consumption pattern } & \multirow[b]{2}{*}{$n$} & Food securet ( $n$ 92) & \multicolumn{3}{|c|}{ Individual-level food insecurity (n 372) } & \multicolumn{3}{|c|}{ Child-level food insecurity ( $n$ 550) } \\
\hline & & $\%$ & $\%$ & AOR $\ddagger$ & $95 \% \mathrm{Cl}$ & $\%$ & $\mathrm{AOR} \ddagger$ & $95 \% \mathrm{Cl}$ \\
\hline \multicolumn{9}{|c|}{ Whether eaten several times weekly } \\
\hline Citrus fruits & 334 & $47 \cdot 8$ & $29 \cdot 8$ & $0.52^{\star \star \star}$ & $0.31,0.84$ & $32 \cdot 5$ & $0.54^{*}$ & $0.34,0.85$ \\
\hline Non-citrus fruits & 901 & $95 \cdot 7$ & $86 \cdot 8$ & $0 \cdot 26^{*}$ & $0.08,0.75$ & $89 \cdot 1$ & $0.34^{*}$ & $0.11,0.94$ \\
\hline Green leafy vegetables & 670 & $78 \cdot 3$ & $66 \cdot 7$ & $0.53^{*}$ & $0.30,0.93$ & $63 \cdot 6$ & $0 \cdot 47^{*}$ & $0 \cdot 27,0.80$ \\
\hline Other vegetables & 922 & $97 \cdot 8$ & $90 \cdot 1$ & $0 \cdot 19^{\star}$ & $0.04,0.82$ & $90 \cdot 4$ & $0 \cdot 20^{*}$ & $0.04,0.85$ \\
\hline \multicolumn{9}{|c|}{ Whether eaten at least weekly } \\
\hline Meat & 513 & $87 \cdot 0$ & $53 \cdot 5$ & $0 \cdot 19^{* \star *}$ & $0.09,0.36$ & $42 \cdot 5$ & $0 \cdot 11^{\star \star *}$ & $0.06,0.22$ \\
\hline Fish & 961 & $94 \cdot 6$ & $93 \cdot 8$ & 0.86 & $0 \cdot 30,2 \cdot 42$ & $95 \cdot 5$ & $1 \cdot 14$ & $0.41,3.09$ \\
\hline Chicken & 246 & $35 \cdot 9$ & $22 \cdot 8$ & 0.65 & $0.38,1.08$ & $23 \cdot 3$ & $0 \cdot 59^{\star \star \star}$ & $0.36,0.95$ \\
\hline Eggs & 453 & $62 \cdot 0$ & $39 \cdot 0$ & $0 \cdot 48^{* \star *}$ & $0.29,0.79$ & $45 \cdot 6$ & $0 \cdot 56^{\star \star \star}$ & $0.35,0.88$ \\
\hline
\end{tabular}

tFood secure as the reference category.

$\ddagger$ Odds ratio adjusted for age, sex, marital status, education level and occupation.

Statistical significance: ${ }^{\star} P<0 \cdot 05,{ }^{\star \star \star} P<0.001$

Table 3 Anthropometric characteristicst of study participants by food insecurity status: adults aged 15-44 years with children in rural Kilimanjaro, Tanzania, 2005

\begin{tabular}{|c|c|c|c|c|c|c|c|}
\hline \multirow[b]{2}{*}{ Variable } & \multicolumn{2}{|c|}{ Food secure } & \multicolumn{2}{|c|}{ Household-level food insecurity } & \multicolumn{2}{|c|}{ Child-level food insecurity } & \multirow[b]{2}{*}{$P$ value } \\
\hline & Mean & SD & Mean & SD & Mean & SD & \\
\hline Men & \multicolumn{2}{|c|}{$n 18$} & \multicolumn{2}{|c|}{$n 133$} & \multicolumn{2}{|c|}{$n 160$} & \\
\hline Weight (kg) & $58 \cdot 5$ & $7 \cdot 3$ & $57 \cdot 7$ & $7 \cdot 9$ & $58 \cdot 3$ & $8 \cdot 5$ & 0.930 \\
\hline Height $(\mathrm{cm})$ & $167 \cdot 3$ & $5 \cdot 9$ & $165 \cdot 9$ & $7 \cdot 6$ & $166 \cdot 5$ & $7 \cdot 1$ & 0.681 \\
\hline BMI $\left(\mathrm{kg} / \mathrm{m}^{2}\right)$ & $20 \cdot 9$ & $2 \cdot 5$ & $21 \cdot 0$ & $2 \cdot 8$ & $21 \cdot 0$ & $2 \cdot 8$ & 0.965 \\
\hline Waist circumference $(\mathrm{cm})$ & $76 \cdot 8$ & $5 \cdot 2$ & $77 \cdot 6$ & $8 \cdot 3$ & $76 \cdot 2$ & $8 \cdot 0$ & $0 \cdot 351$ \\
\hline Hip circumference $(\mathrm{cm})$ & $88 \cdot 7$ & $5 \cdot 1$ & 86.9 & $9 \cdot 6$ & $88 \cdot 0$ & $10 \cdot 4$ & 0.860 \\
\hline WHR & 0.66 & $0 \cdot 60$ & 0.68 & $0 \cdot 17$ & 0.68 & $0 \cdot 18$ & $0 \cdot 898$ \\
\hline Women & \multicolumn{2}{|c|}{$n 73$} & \multicolumn{2}{|c|}{$n 236$} & \multicolumn{2}{|c|}{$n 387$} & \\
\hline Weight (kg) & $57 \cdot 4$ & $10 \cdot 5$ & $56 \cdot 9$ & $10 \cdot 8$ & $55 \cdot 1$ & $9 \cdot 7$ & $0 \cdot 103$ \\
\hline Height $(\mathrm{cm})$ & $157 \cdot 1$ & $6 \cdot 6$ & $156 \cdot 7$ & $7 \cdot 4$ & $157 \cdot 4$ & $7 \cdot 4$ & 0.235 \\
\hline BMI $\left(\mathrm{kg} / \mathrm{m}^{2}\right)$ & $23 \cdot 3$ & 3.9 & $23 \cdot 2$ & $4 \cdot 2$ & $22 \cdot 3$ & 3.9 & $0.038^{*}$ \\
\hline Waist circumference $(\mathrm{cm})$ & $78 \cdot 0$ & $9 \cdot 7$ & $80 \cdot 1$ & $10 \cdot 5$ & $76 \cdot 8$ & $12 \cdot 4$ & $0.026^{*}$ \\
\hline Hip circumference (cm) & $92 \cdot 0$ & $12 \cdot 0$ & $94 \cdot 6$ & $11 \cdot 8$ & $92 \cdot 1$ & $12 \cdot 3$ & $0 \cdot 221$ \\
\hline WHR & 0.63 & $0 \cdot 17$ & 0.60 & 0.08 & 0.61 & $0 \cdot 15$ & 0.073 \\
\hline
\end{tabular}

WHR, waist:hip ratio.

tAdjusted for age, marital status, education level and occupation.

Statistical significance: ${ }^{\star} P<0.05$. 
Table 4 Distribution of BMI and central obesity of study participants according to food insecurity status: adults aged 15-44 years with children in rural Kilimanjaro, Tanzania, 2005

\begin{tabular}{|c|c|c|c|c|}
\hline Variable & Food secure (\%) & Household-level food insecurity (\%) & Child-level food insecurity (\%) & $P$ value \\
\hline $\begin{array}{l}\text { Men } \\
\text { BMI category }\end{array}$ & $n 18$ & $n 133$ & $n 160$ & \\
\hline $\begin{array}{l}<18.5 \mathrm{~kg} / \mathrm{m}^{2} \\
<I V I\end{array}$ & $11 \cdot 1$ & $12 \cdot 8$ & $9 \cdot 4$ & \\
\hline $18 \cdot 5-24 \cdot 9 \mathrm{~kg} / \mathrm{m}^{2}$ & $77 \cdot 8$ & $77 \cdot 4$ & $79 \cdot 4$ & \\
\hline $25.0-29.9 \mathrm{~kg} / \mathrm{m}^{2}$ & $11 \cdot 1$ & $9 \cdot 0$ & $9 \cdot 4$ & \\
\hline$\geq 30 \cdot 0 \mathrm{~kg} / \mathrm{m}^{2}$ & 0.0 & 0.8 & 1.9 & 0.934 \\
\hline \multicolumn{5}{|l|}{ Central obesity } \\
\hline No & 100.0 & $98 \cdot 5$ & $97 \cdot 5$ & \\
\hline Yes & 0.0 & $1 \cdot 5$ & $2 \cdot 5$ & 0.677 \\
\hline Women & $n 73$ & $n 236$ & $n 386$ & \\
\hline \multicolumn{5}{|l|}{ BMI category } \\
\hline$<18.5 \mathrm{~kg} / \mathrm{m}^{2}$ & $5 \cdot 5$ & $5 \cdot 1$ & $7 \cdot 3$ & \\
\hline $18 \cdot 5-24 \cdot 9 \mathrm{~kg} / \mathrm{m}^{2}$ & $61 \cdot 6$ & $59 \cdot 7$ & $69 \cdot 2$ & \\
\hline $25 \cdot 0-29 \cdot 9 \mathrm{~kg} / \mathrm{m}^{2}$ & $23 \cdot 3$ & $27 \cdot 1$ & $18 \cdot 4$ & \\
\hline$\geq 30.0 \mathrm{~kg} / \mathrm{m}^{2}$ & $9 \cdot 6$ & $8 \cdot 1$ & $5 \cdot 2$ & 0.075 \\
\hline \multicolumn{5}{|l|}{ Central obesity } \\
\hline No & $95 \cdot 7$ & $99 \cdot 6$ & $97 \cdot 4$ & \\
\hline Yes & $4 \cdot 3$ & 0.4 & $2 \cdot 6$ & 0.064 \\
\hline
\end{tabular}

tCentral obesity classified as waist:hip ratio $\geq 0.85$ for women and $\geq 0.95$ for men.

central obesity $(P=0 \cdot 064)$, as did BMI categories $(P=0 \cdot 075)$, with food insecurity status (Table 4$)$. Further analysis using regression models did not reveal any significant associations.

\section{Food insecurity and serum micronutrient levels}

The mean (SD) serum ferritin level was 58.6 (115.8) $\mu \mathrm{g} / \mathrm{l}$ and mean (SD) serum vitamin A level was $1.26(0.52)$ $\mu \mathrm{mol} / 1$. Iron depletion was prevalent in $23.5 \%$ (230/979) of the respondents and vitamin A deficiency was observed in $10 \cdot 7 \%(104 / 971)$ of the respondents. There was no correlation between food insecurity status and iron depletion or vitamin A deficiency.

\section{Discussion}

The present study assessed the association between food insecurity status and food consumption patterns, anthropometric measures and serum micronutrient levels among adults in rural Kilimanjaro, Tanzania. The overall prevalence of food insecurity in this rural area was high. Food insecurity status was associated with selected demographic characteristics at both the individual and child level. These findings are similar to observations from other studies in developed countries ${ }^{(22)}$ as well as developing countries $^{(8-10,23,24)}$. Contrary to findings from studies conducted in other developing countries ${ }^{(8-10,23,24)}$, we observed no significant association between food insecurity and education. Although the majority of participants reported attending primary school, this has been described as insufficient to reduce poverty ${ }^{(25)}$. Further, a small number of participants reported having secondary education or higher which limited our statistical power to detect any differences.

We also observed a larger proportion of married men and women reporting children experiencing food insecurity compared with those who were single. In their study in the USA, Hanson et al. ${ }^{(26)}$ observed that divorced men reported more food insecurity than never-married men. The disparity in our observation may be due to differences in the tool used to assess food insecurity and categorization of food insecurity. Additionally, differences in the study populations as well as socio-cultural factors may put more pressure on married adults in a Tanzanian context that may lead to more severe food insecurity experiences.

Data obtained on food frequency intake revealed that participants who were food insecure had low intakes of animal products, fruits and vegetables compared with foodsecure participants. The low dietary intakes of animal products, fruits and vegetables in food-insecure individuals are consistent with the findings from other studies ${ }^{(8-10,24,27)}$. The magnitude of the difference in food consumption between food-secure and food-insecure respondents was larger for meat and eggs. This may be because foods of animal origin are generally expensive and unaffordable to the majority of the rural population, while plant sources are less costly ${ }^{(15,28)}$. Vegetables in Africa are said to play a vital role in food security, particularly for the poor, in both rural and urban settings ${ }^{(13,29)}$. It is estimated that about $80 \%$ of rural Tanzanians rely on home-grown fruits and vegetables particularly during the lean rainy seasons as a primary food and relish ${ }^{(13,15,30,31)}$. The magnitude of the difference in fruit and vegetable consumption between food-secure and food-insecure individuals may widen during the dry season as vegetables become scarce and households rely more on markets $^{(11,13)}$.

Fruits and vegetables offer a great source of micronutrients if prepared properly and taken in adequate amounts. The prevalence of both iron depletion and vitamin A deficiency indicates that they were common in the study population. However, there was no difference in the proportion of adults who were either iron depleted 
or vitamin A deficient by food insecurity status. Low serum levels of micronutrients including vitamin A, carotenoids and vitamin $\mathrm{E}$ have been described among adults from food-insufficient families in developed countries ${ }^{(32)}$. Our findings show that a modest proportion of the population consumed fruits and vegetables regularly. The ready availability of leafy green vegetables from home gardens during the rain season may have allowed for most of the micronutrient requirements of the population to be met $^{(31)}$. However, the lack of correlation between food insecurity status and micronutrient status may be explained by: (i) small variation in the bioavailability of iron and pro-vitamin $\mathrm{A}$ in the fruits and vegetables consumed as a result of nutrient loss during preparation ${ }^{(30)}$; (ii) the cut-off points used were based on acute manifestations of micronutrient deficiencies; (iii) some nutrients such as vitamin A are tightly regulated by the liver and not affected by recent dietary intake; and (iv) some infections can influence serum ferritin levels in the body ${ }^{(33)}$. More studies are needed to assess food preparation habits of food-secure and food-insecure households and the influence it may have on micronutrient status.

There are plausible biological mechanisms to suggest that food insecurity has negative health outcomes on those experiencing $i^{(3)}$. Studies assessing the association between food insecurity and nutritional status in both developed $^{(34-36)}$ and developing countries ${ }^{(8,10)}$ have produced conflicting results. Our findings suggest that increased adiposity among women may be associated with food insecurity at the individual level while decreased adiposity among women may be associated with food insecurity at the child level; similar to what other studies have observed ${ }^{(10,11,37)}$. In light of the prevalence of food insecurity, it is expected that underweight due to a lack of adequate food would be the primary manifestation of food insecurity in this setting; however, nutritional status assessed by anthropometric measures is considered a distal outcome of food insecurity and is not only determined by access to food ${ }^{(11)}$. The lack of a significant association between food insecurity and anthropometric measures in the multivariable analysis may be because of the time lag between inadequate food intake and observable physical changes. Moreover, anthropometric measures are sensitive to other variables such as infection, sanitation and hygiene ${ }^{(17)}$. Our study was conducted at the onset of the pre-harvest lean (rainy) season when food shortages and increased energy expenditure from agricultural work had just begun. Thus, physical changes may not have occurred sufficiently to be detected during the survey. Further studies are needed to examine changes in nutritional status that accompany seasonal variation in food insecurity in rural Tanzania.

Limitations of the present study lie in the temporal nature of the data, specifically the fact that food insecurity data were not coincident with data on food consumption, anthropometry and micronutrient status. This raises important questions about cause and effect. Another limitation is the use of a non-validated FFQ to assess dietary patterns. The inherent recall bias associated with the FFQ would make it less likely to correctly describe usual dietary intake. However, allowing for control of factors known to influence under-reporting such as age, sex and education and pre-testing of the FFQ, we believe our results are a fair representation of actual dietary patterns ${ }^{(38)}$. The strength of the present survey lies in the use of a validated self-report measure of food insecurity, assessing food insecurity at an individual level to allow direct comparison with nutritional outcomes, and inclusion of the whole adult population with a fairly good response proportion.

\section{Conclusion}

Our study has shown that food insecurity was highly prevalent and associated with food consumption patterns, waist circumference and BMI of women in rural Tanzania. Further studies should apply self-report measures in assessing food insecurity to larger and more diversified populations.

\section{Acknowledgements}

Sources of funding: The study was supported by a grant from the Norwegian Programme for Development, Research and Higher Education (NUFU) and the Centre for Prevention of Global Infections (GLOBINF) at the University of Oslo, Norway. The study was facilitated by the collaborating institutions: Muhimbili University of Health Sciences, Kilimanjaro Christian Medical College, the Centre for Education Development (Arusha, Tanzania), and the Universities of Oslo and Bergen, Norway. Conflict of interest declaration: None. Authors' contributions: G.H.L., conception of study, data collection, analysis and interpretation of results, drafting of manuscript; E.J.M., conception of study, data collection, review of manuscript; K.S.M., data collection, review of manuscript; A.H., interpretation of results, review of manuscript; K.-I.K., conception of study, interpretation of results, critical review of manuscript. Acknowledgements: The authors are grateful to the participants for their time and to the hardworking spirit of the research team.

\section{References}

1. Food and Agriculture Organization of the United Nations (1998) Rome Declaration on World Food Security. World Food Summit 1996. Rome: FAO.

2. Food and Agriculture Organization of the United Nations (2006) The State of Food Insecurity in the World 2006. Rome: FAO.

3. Campbell CC (1991) Food insecurity: a nutritional outcome or a predictor variable? J Nutr 121, 408-415. 
4. Frongillo EA, Olson CM, Rauschenbach BA et al. (1997) Nutrition Consequences of Food Insecurity in a Rural New York State County. Discussion Paper no. 1120-97. Madison, WI: Institute for Research on Poverty.

5. Olson CM (1999) Nutrition and health outcomes associated with food insecurity and hunger. J Nutr 129, 2S Suppl., 521S-524S.

6. Tarasuk VS \& Beaton GH (1999) Women's dietary intakes in the context of household food insecurity. I Nutr $\mathbf{1 2 9}$, 672-679.

7. Tarasuk VS (2001) Household food insecurity with hunger is associated with women's food intakes, health and household circumstances. J Nutr 131, 2670-2676.

8. Gulliford MC, Mahabir D \& Rocke B (2003) Food insecurity, food choices, and body mass index in adults: nutrition transition in Trinidad and Tobago. Int J Epidemiol 32, 508-516.

9. Nnakwe N \& Yegammia C (2002) Prevalence of food insecurity among households with children in Coimbatore, India. Nutr Res 22, 1009-1016.

10. Shariff ZM \& Khor GL (2005) Obesity and household food insecurity: evidence from a sample of rural households in Malaysia. Eur J Clin Nutr 59, 1049-1058.

11. Frongillo EA \& Nanama S (2006) Development and validation of an experience-based measure of household food insecurity within and across seasons in Northern Burkina Faso. J Nutr 136, 1409S-1419S.

12. Zalilah MS \& Ang M (2001) Assessment of food insecurity among low income households in Kuala Lumpur using the Radimer/Cornell food insecurity instrument - a validation study. Malays J Nutr 7, 15-32.

13. Kinabo J, Mnkeni AP, Nyaruhucha CNM et al. (2006) Feeding frequency and nutrient content of foods commonly consumed in the Iringa and Morogoro regions in Tanzania. Int J Food Sci Nutr 57, 9-17.

14. Maruapula S \& Chapman-Novakofski K (2007) Health and dietary patterns of the elderly in Botswana. J Nutr Educ Behav 39, 311-319.

15. Mazengo MC, Simell O, Lukumanji A et al. (1997) Food consumption in rural and urban Tanzania. Acta Trop 68, 313-326.

16. Tatala S, Svanberg U \& Mduma B (1998) Low dietary iron availability is a major cause of anemia: a nutrition survey in the Lindi district of Tanzania. Am J Clin Nutr 68, 171-178.

17. UNICEF (1990) Strategy for Improved Nutrition of Children and Women in Developing Countries. A UNICEF Policy Review. New York: UNICEF.

18. Leyna GH, Mmbaga EJ, Mnyika KS et al. (2008) Validation of the Radimer/Cornell food insecurity measure in rural Kilimanjaro, Tanzania. Public Health Nutr 11, 684-689.

19. Klouman E, Masenga EJ, Klepp KI et al. (1997) HIV and reproductive tract infections in a total village population in rural Kilimanjaro, Tanzania: women at increased risk. J Acquir Immune Defic Syndr Hum Retrovirol 14, 163-168.

20. Ottesen M (2003) Self-perceived food security among school adolescents in a rural area of northern Tanzania. Dissertation, University of Oslo.

21. World Health Organization (1995) Physical Status: The Use and Interpretation of Anthropometry. Report of a WHO Expert Committee. Geneva: WHO.
22. Furness BW, Simon PA, Wold CM et al. (2004) Prevalence and predictors of food insecurity among low-income households in Los Angeles County. Public Health Nutr 7, 791-794

23. Isanaka S, Mora-Plazas M, Lopez-Arana S et al. (2007) Food insecurity is highly prevalent and predicts underweight but not overweight in adults and school children from Bogotá, Columbia. J Nutr 137, 2747-2755.

24. Zerafati-Shoae N, Omidvar N, Ghazi-Tabatabaie $\mathrm{M}$ et al. (2007) Is the adapted Radimer/Cornell questionnaire valid to measure food insecurity of urban households in Tehran, Iran? Public Health Nutr 10, 855-861.

25. Wedgewood R (2007) Education and poverty reduction in Tanzania. Int J Educ Dev 27, 383-396.

26. Hanson KL, Sobal J \& Frongillo EA (2007) Gender and marital status clarify associations between food insecurity and body weight. $J$ Nutr 137, 1460-1465.

27. Hadley C, Mulder MB \& Fitzherbert E (2007) Seasonal food insecurity and perceived social support in rural Tanzania. Public Health Nutr 10, 544-551.

28. Codjia G (2001) Food sources of vitamin A and provitamin A specific to Africa: an FAO perspective. Food Nutr Bull 22, 357-360.

29. Weinberger K \& Msuya J (2004) Indigenous Vegetables in Tanzania: Significance and Prospects. Technical Bulletin no. 31. Tainan, Taiwan: The World Vegetable Center.

30. Mulokozi G, Lietz G, Svanberg U et al. (2003) Plasma levels of retinol, carotenoids, and tocopherols in relation to dietary pattern among pregnant Tanzanian women. Int $J$ Vitam Nutr Res 73, 323-333.

31. Tanner M \& Lukmanji Z (1987) Food consumption patterns in a rural Tanzanian community (Kikwawila village, Kilombero District, Morogoro Region) during lean and postharvest season. Acta Trop 44, 229-244.

32. Dixon LB, Winkleby MA \& Radimer KL (2001) Dietary intakes and serum nutrients differ between adults from food-insufficient and food-sufficient families: Third National Health and Nutrition Examination Survey, 1988-1994. J Nutr 131, 1232-1246.

33. Hulthén L, Lindstedt G, Lundberg P-A et al. (1998) Effect of a mild infection on serum ferritin concentration - clinical and epidemiological implications. Eur J Clin Nutr 52, 376-379.

34. Townsend MS, Peerson J, Love B et al. (2001) Food insecurity is positively related to overweight in women. J Nutr 131, 1738-1745.

35. Whitaker RC \& Sarin A (2007) Changes in food security status and change in weight are not associated in urban women with preschool children. J Nutr 137, 2134-2139.

36. Wilde PE \& Peterman JN (2006) Individual weight change is associated with household food security status. J Nutr 136, 1395-1400.

37. Chaput JP, Gilbert JA \& Tremblay A (2007) Relationship between food insecurity and body composition in Ugandans living in urban Kampala. J Am Diet Assoc 107, 1978-1982.

38. Bedard D, Shatenstein B \& Madon S (2004) Underreporting of energy intake from a self-administered food frequency questionnaire completed by adults in Montreal. Public Health Nutr 7, 675-681. 